ORIGINAL ARTICLE

\title{
Clinical detection of low upper body blood flow in very premature infants using blood pressure, capillary refill time, and central-peripheral temperature difference
}

\author{
D A Osborn, N Evans, M Kluckow
}

Arch Dis Child Fetal Neonatal Ed 2004;89:F168-F173. doi: 10.1136/adc.2002.023796

\begin{abstract}
See end of article for authors' affiliations

Correspondence to: Dr Osborn, Department of Neonatal Medicine, Royal Prince Alfred Hospital, Missenden Rd, Camperdown, NSW, Australia 2050; david.osborn@ email.cs.nsw.gov.au
\end{abstract}

Accepted 10 March 2003

\begin{abstract}
Objective: To determine the accuracy of blood pressure (BP), capillary refill time (CRT), and centralperipheral temperature difference (CPTd) for detecting low upper body blood flow in the first day after birth.

Methods: A prospective, two centre cohort study of 128 infants born at $<30$ weeks gestation. Invasive BP ( $n=108)$, CRT $(n=128)$, and CPTd $(n=46)$ were performed immediately before echocardiographic measurement of superior vena cava (SVC) flow at three, 5-10, and 24 hours after birth.

Results: Forty four (34\%) infants had low SVC flow $(<41 \mathrm{ml} / \mathrm{kg} / \mathrm{min})$ in the first day, $13 / 122(11 \%)$ at three hours, $39 / 126(31 \%)$ at 5-10 hours, and $4 / 119(3 \%)$ at 24 hours. CPTd did not detect infants with low flows. Combining all observations in the first 24 hours, CRT $\geqslant 3$ seconds had $55 \%$ sensitivity and $81 \%$ specificity, mean BP $<30 \mathrm{~mm} \mathrm{Hg}$ had $59 \%$ sensitivity and $77 \%$ specificity, and systolic BP $<40 \mathrm{~mm} \mathrm{Hg}$ had $76 \%$ sensitivity and $68 \%$ specificity for detecting low SVC flow. Combining a mean BP $<30 \mathrm{~mm} \mathrm{Hg}$ and/or central CRT $\geqslant 3$ seconds increases the sensitivity to $78 \%$.

Conclusions: Low upper body blood flow is common in the first day after birth and strongly associated with peri/intraventricular haemorrhage. BP and CRT are imperfect bedside tests for detecting low blood flow in the first day after birth.
\end{abstract}

predictor of $\mathrm{P} / \mathrm{IVH}^{14}$ and poor neurodevelopmental outcome $\mathrm{e}^{15}$ than blood pressure. Therefore, accurate clinical detection of low SVC flow is an important clinical goal.

The aim of this study was to determine the accuracy of capillary refill time (CRT), central-peripheral temperature difference (CPTd), and blood pressure (BP) for detecting low blood flow to the brain and upper body in premature infants in the first day after birth.

\section{METHODS}

The study was a two centre, prospective cohort study of premature infants born at $<30$ weeks gestation. The study was carried out in the Royal Prince Alfred and Royal North Shore Hospital neonatal intensive care units, Sydney, Australia between October 1998 and December 1999. The ethics committees of Central Sydney and Northern Sydney Area Health Services approved the study. Informed consent was obtained from all parents.

\section{Infants}

Infants born at $<30$ weeks gestation and $<12$ hours of age were eligible. Informed consent was obtained antenatally where possible. Infants were excluded if parental consent was refused, a major congenital abnormality or cardiac abnormality was identified, the infant was considered by the attending clinician to be non-viable, or if inotrope or indomethacin had been given before three hours after birth. Most infants were nursed in humidified cribs to maintain

Abbreviations: BP, blood pressure; CPTd, central peripheral temperature difference; CRT, capillary refill time; $L R+$, positive likelihood ratio; $L R-$, negative likelihood ratio; NPV, negative predictive value; P/ $\mathrm{IVH}$, peri/intraventricular haemorrhage; PPV, positive predictive value; ROC, receiver operator curve; SBF, systemic blood flow; $\mathrm{Sn}$, sensitivity; $\mathrm{Sp}$, specificity; SVC, superior vena cava output and hyperkalaemia, ${ }^{20}$ mortality, ${ }^{13}$ and poor neurodevelopmental outcome. ${ }^{15}$ Low SVC flow was a better 
central temperature $\geqslant 36.5^{\circ} \mathrm{C}$ and with humidity $\geqslant 80 \%$. CPTd was not used to adjust crib temperature.

\section{Clinical and physiological data}

CRT, CPTd, and systolic and mean BP measurements were taken before each scan. A single investigator (DO) performed all clinical measurements after a period of thermal stability (undisturbed for at least 15 minutes). CRT was measured in all 128 enrolled infants, centrally on the anterior chest and peripherally on the palm of the hand. An index finger was used to apply sufficient pressure to blanch the skin for five seconds, and a stopwatch was used to time return to normal skin colour. Two consecutive reproducible results were taken as the true CRT.

Central-peripheral temperature was monitored in a subgroup of 46 infants enrolled at one centre (Royal Prince Alfred Hospital) and nursed in Dräger 8000ic humidicribs. Dräger Thermoview continuous central and peripheral temperature monitoring was used. Central temperature was recorded by placing the sensor at the thorax/bed interface, which has been shown to be an accurate measure of core temperature. $^{21}$ Peripheral temperature was recorded by placing the sensor on the sole of the infant's foot. The temperature probes were secured using a hydrocolloid transparent dressing. CPTd was recorded after a 15 minute period of stability before echocardiography.

Invasive arterial monitoring using umbilical or peripheral arterial catheters was available in 108 of the 128 infants enrolled. Systolic and mean BP were recorded over 10 cardiac cycles before echocardiography.

\section{Echocardiographic monitoring, blood flow measurement, and cardiovascular support}

Echocardiographic monitoring was performed routinely at three, 5-10, and 24 hours of age. The 5-10 hour scan is taken as the scan before the start of volume expansion and inotropes if used, or the scan closest to 10 hours of age. Low SBF was defined as SVC flow $<41 \mathrm{ml} / \mathrm{kg} / \mathrm{min}$ from previous data in healthy preterm babies. ${ }^{19}$ An Acuson (Mountain View, California, USA) 128/XP10 ultrasound scanner was used with a $7 \mathrm{MHz}$ vector array transducer incorporating colour flow and pulsed wave Doppler. The scan was recorded on to VHS videotape, and the measurements then taken from the videotape. Structural normality of the heart was established on the initial scan. SVC flow was determined as described previously. ${ }^{19}$ A clinically significant patent ductus arteriosus was defined as a ductus with a colour Doppler diameter $>1.6 \mathrm{~mm}$ from previous studies. ${ }^{22-24}$

Infants who were identified on echocardiography as having a ductus arteriosus $>1.6 \mathrm{~mm}$ were given indomethacin. ${ }^{25}$ Infants who were identified as having low SVC flow $(<41 \mathrm{ml} / \mathrm{kg} / \mathrm{min})$ were treated with volume expansion (normal saline $10 \mathrm{ml} / \mathrm{kg}$ ) and inotropes (dopamine and/or dobutamine) ${ }^{26}$

\section{Statistical analysis}

Data were analysed with a PC based statistics package (SPSS release 10.0.7 for Windows) using $t$ test for continuous variables, and the two sided $\chi^{2}$ test or Fisher exact test where appropriate for dichotomous variables. The Pearson correlation coefficient was used to assess the linear correlation between variables where appropriate. Confidence intervals for diagnostic test accuracy were calculated using the Newcombe-Wilson hybrid score (not continuity corrected). ${ }^{27}$ Receiver operator curves (ROC) and area under the ROC (with 95\% confidence interval (CI)) were calculated using SPPS.

\section{RESULTS}

\section{Study population}

Between October 1998 and December 1999, 160 infants from 23 to 29 weeks gestation were admitted to the neonatal units (100 to Royal Prince Alfred Hospital and 60 to Royal North Shore Hospital). Consent was not obtained or an investigator was not available for $32(20 \%)$ infants. The mean gestation (27.1 $v 26.8$ weeks) and birth weight (1078 $v 986 \mathrm{~g}$ ) of nonenrolled infants was not significantly higher than enrolled infants. A total of 128 infants with consent underwent clinical and echocardiographic monitoring in the first 24 hours after birth.

Echocardiography was performed on 122 infants at three hours, 126 at 5-10 hours, and 119 infants at 24 hours. A total of 80 infants $(63 \%)$ with a significant ductus arteriosus (colour Doppler diameter $>1.6 \mathrm{~mm}$ ) received indomethacin. Forty four (34\%) of 128 infants were identified with low SVC flow in the first 24 hours after birth (table 1). Low SVC flow was identified in 13/122 (11\%) at three hours, 39/126 (31\%) at 5-10 hours, and 4/119 (3\%) at 24 hours. All 44 infants (34\%) with low SVC flow in the first 24 hours after birth received volume expansion and inotropes, either dopamine and/or dobutamine. Therefore, no infant had received indomethacin or inotropes at the three hour measurement. At 5-10 hours, 79/126 infants had received indomethacin, and seven infants were receiving inotrope. At 24 hours, 75/119 had received indomethacin, and 39 were receiving inotropes (14 dobutamine, 16 dopamine, and nine both dobutamine and dopamine).

\section{Central-peripheral temperature difference}

Forty six infants had central-peripheral temperature measurements taken before flow measurements (table 2). SVC flow $<41 \mathrm{ml} / \mathrm{kg} / \mathrm{min}$ was present in $7 / 43(16 \%)$ infants at three hours, $17 / 46$ (37\%) infants at 5-10 hours, and 1/43 $(2 \%)$ at 24 hours. Combining the three sets of observations (fig 1) results in a pretest probability of low flow of 19\% (25/ 132). There was no correlation between CPTd and SVC flow (Pearson $r=0.02, \mathrm{p}=0.8$ ). The area under the ROC was 0.47 ( $95 \%$ CI 0.35 to 0.61 ). The post-test probabilities of low flow were not significantly different from the pretest probabilities (table 3 ).

Table 1 Perinatal variables and outcomes of preterm infants with low superior vena cava flow $(<41 \mathrm{ml} / \mathrm{kg}$ / $\mathrm{min}$ ) detected in the first 24 hours after birth

\begin{tabular}{llll}
\hline & $\begin{array}{l}\text { Normal flow } \\
(\mathbf{n = 8 4 )}\end{array}$ & $\begin{array}{l}\text { Low flow } \\
(\mathbf{n}=44)\end{array}$ & p Value \\
\hline Mean (SD) gestation (weeks) & $27.4(1.6)$ & $25.8(1.8)$ & $<0.001$ \\
Mean (SD) birth weight (g) & $1027(276)$ & $916(271)$ & 0.03 \\
$\leqslant \quad$ Oth percentile & $11(13 \%)$ & $1(2 \%)$ & 0.06 \\
Male & $36(43 \%)$ & $23(52 \%)$ & 0.3 \\
Antenatal steroids & & & \\
$\quad$ Any & $81(96 \%)$ & $37(84 \%)$ & 0.03 \\
$\quad$ Complete & $60(71 \%)$ & $21(48 \%)$ & 0.008 \\
Antihypertensives & $21(25 \%)$ & $2(5 \%)$ & 0.004 \\
Labour & $56(67 \%)$ & $34(77 \%)$ & 0.2 \\
Caesarean & $50(60 \%)$ & $23(52 \%)$ & 0.4 \\
Ex utero & $6(7 \%)$ & $8(18 \%)$ & 0.08 \\
Apgar $\leqslant 4$ at 1 minute & $29(35 \%)$ & $22(50 \%)$ & 0.09 \\
Ventilated & $71(85 \%)$ & $44(100 \%)$ & 0.004 \\
Respiratory distress syndrome & $57(68 \%)$ & $36(82 \%)$ & 0.09 \\
Patent ductus arteriosus & $47(56 \%)$ & $33(75 \%)$ & 0.03 \\
Peri/intraventricular & & & \\
haemorrhage & & & \\
$\quad$ Any grade \\
Grade 3-4 & $17(20 \%)$ & $21(48 \%)$ & 0.001 \\
Died & $5(6 \%)$ & $12(27 \%)$ & 0.001 \\
\hline & $11(13 \%)$ & $25(57 \%)$ & $<0.001$ \\
\hline & & & \\
\hline
\end{tabular}


Table 2 Use of central-peripheral temperature difference (CPTd), capillary refill time (CRT), mean and systolic blood pressure (BP) to predict low superior vena cava flow $(<41 \mathrm{ml} / \mathrm{kg} / \mathrm{min}$ ) in preterm infants $<30$ weeks gestation. Combined observations and conditional likelihood ratios in first 24 hours

\begin{tabular}{|c|c|c|c|}
\hline & $\begin{array}{l}\text { Normal } \\
\text { flow }\end{array}$ & Low flow & Total \\
\hline \multicolumn{4}{|l|}{ CPTd } \\
\hline$<2^{\circ} \mathrm{C}$ & 74 & 15 & 89 \\
\hline$\geqslant 2^{\circ} \mathrm{C}$ & 33 & 10 & 43 \\
\hline Total & 107 & 25 & 132 \\
\hline \multicolumn{4}{|l|}{ CRT } \\
\hline$<3$ seconds & 249 & 25 & 274 \\
\hline $3-3.9$ seconds & 49 & 15 & 64 \\
\hline$\geqslant 4$ seconds & 13 & 16 & 29 \\
\hline Total & 311 & 56 & 367 \\
\hline \multicolumn{4}{|l|}{ Systolic BP } \\
\hline$\geqslant 48 \mathrm{~mm} \mathrm{Hg}$ & 89 & 4 & 93 \\
\hline $40-47.9 \mathrm{~mm} \mathrm{Hg}$ & 81 & 9 & 90 \\
\hline$<40 \mathrm{~mm} \mathrm{Hg}$ & 81 & 41 & 122 \\
\hline Total & 251 & 54 & 305 \\
\hline \multicolumn{4}{|l|}{ Mean BP } \\
\hline$\geqslant 30 \mathrm{~mm} \mathrm{Hg}$ & 193 & 22 & 215 \\
\hline$<30 \mathrm{~mm} \mathrm{Hg}$ & 58 & 32 & 90 \\
\hline Total & 251 & 54 & 305 \\
\hline$>$ Gestation & 220 & 38 & 258 \\
\hline$\leqslant$ Gestation* & 31 & 16 & 47 \\
\hline Total & 251 & 54 & 305 \\
\hline
\end{tabular}

\section{Capillary refill time}

Central and peripheral CRT were measured in all 128 infants before flow measurements (table 2), with 13/122 (11\%) at three hours, 39/126 (31\%) at 5-10 hours, and 4/119 (3\%) at 24 hours having low SVC flow. The sensitivity and specificity of the CRT at three and 5-10 hours were similar, as were the results of the central and peripheral CRT. Combining the three sets of observations (fig 2) results in a pretest probability of low flow of $15 \%$ (56/367). There was a significant correlation between both central (Pearson $r=0.42, \mathrm{p}<0.001$ ) and peripheral (Pearson $r=0.38$, $\mathrm{p}<0.001)$ CRT and SVC flow. A central CRT $\geqslant 3$ seconds had a sensitivity of $55 \%$ and specificity of $80 \%$ for low SVC flow (table 3$)$. The confidence intervals of the positive predictive value (PPV) $(33 \%, 95 \%$ CI 29 to 38\%) and negative predictive value (NPV) $(91 \%, 95 \%$ CI 88 to 94\%) values do not include the pretest probabilities. A central CRT $\geqslant 4$ seconds increased the specificity (96\%) and PPV (55\%) but reduced the sensitivity (29\%). The area under the ROC was 0.72 (95\% CI 0.64 to 0.80$)$. A sensitivity of $90 \%$ was produced at a central CRT $\geqslant 1.9$ seconds, but resulted in only $19 \%$ specificity.

\section{Blood pressure}

Invasive BP measurements (table 3) were performed on 108 infants before flow measurements, with 13/97 (13\%) at three hours, $37 / 108(34 \%)$ at 5-10 hours, and 4/100 (4\%) at 24 hours having low flow. Combining the three sets of observations (mean BP (fig 3); systolic BP (fig 4)) results in a pretest probability of low flow of $18 \%(54 / 305)$. There was a weak but significant correlation between both mean (Pearson $r=0.23, \mathrm{p}<0.001$ ) and systolic (Pearson $r=0.26$, $\mathrm{p}<0.001) \mathrm{BP}$ and SVC flow in the first 24 hours. The area under the ROC was 0.78 (95\% CI 0.64 to 0.80 ) for systolic BP and 0.75 (95\% CI 0.67 to 0.82 ) for mean BP. At $90 \%$ sensitivity, a systolic BP $<47 \mathrm{~mm} \mathrm{Hg}$ resulted in $35 \%$ specificity, similar to a mean $\mathrm{BP}<37 \mathrm{~mm} \mathrm{Hg}$ with $33 \%$ specificity.

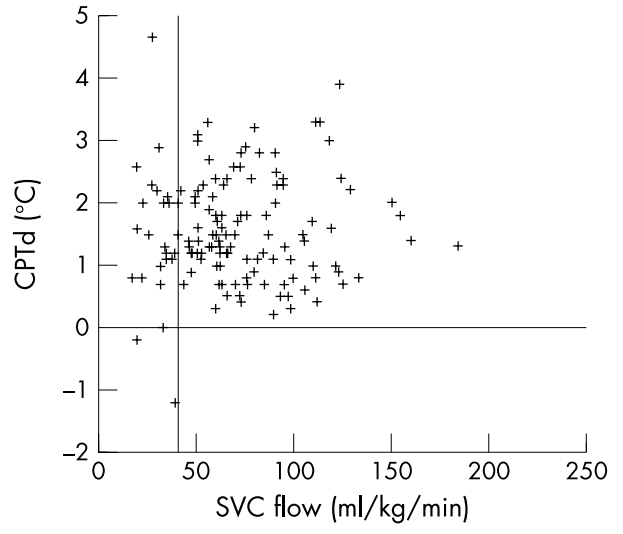

Figure 1 Scatter plot of central-peripheral temperature difference (CPTd) against superior vena cava (SVC) flow for all observations. Reference lines represent SVC flow of $41 \mathrm{ml} / \mathrm{kg} / \mathrm{min}$ and zero CPTd.

A mean $\mathrm{BP}<30 \mathrm{~mm} \mathrm{Hg}$ had 59\% sensitivity and 77\% specificity for low SVC flow (table 4). The confidence intervals of the PPV $(36 \%, 95 \%$ CI 30 to $41 \%)$ and NPV (90\%, 95\% CI 86 to $93 \%$ ) did not include the pretest probabilities. Using a mean $\mathrm{BP} \leqslant$ gestation in weeks reduced the sensitivity to $30 \%$ but increased the specificity to $88 \%$ for low SVC flow.

A systolic $\mathrm{BP}<40 \mathrm{~mm} \mathrm{Hg}$ had $76 \%$ sensitivity and $68 \%$ specificity for low SVC flow. The confidence intervals of the PPV (34\%, 95\% CI 28 to 39\%) and NPV (93\%, 95\% CI 90 to $96 \%$ ) do not include the pretest probabilities. Using a systolic $\mathrm{BP}<48 \mathrm{~mm} \mathrm{Hg}$ increases the sensitivity to $93 \%$ but reduces the specificity to $35 \%$. The NPV (96\%) means an infant with a systolic $\mathrm{BP} \geqslant 48 \mathrm{~mm} \mathrm{Hg}$ is unlikely to have low flows.

Using a criterion of a mean $\mathrm{BP}<30 \mathrm{~mm} \mathrm{Hg}$ and/or central $\mathrm{CRT} \geqslant 3$ seconds has a similar diagnostic accuracy to a systolic $\mathrm{BP}<40 \mathrm{~mm} \mathrm{Hg}$ with $78 \%$ sensitivity, $63 \%$ specificity, PPV $31 \%$ and NPV $88 \%$.

\section{DISCUSSION}

Detecting low SBF early and accurately in the first day has the potential to allow effective targeting of cardiovascular interventions aimed at improving blood flow and reducing neonatal mortality and morbidity. This study found that systolic and mean BP have clinical utility but are imperfect predictors of low SVC flow. A mean $\mathrm{BP} \leqslant$ gestation in weeks detects only $30 \%$ of infants with low flow. Increasing the cut off to $<30 \mathrm{~mm} \mathrm{Hg}$ detects nearly twice as many infants. This may be a better cut off, as it has been associated with neonatal mortality and cerebral injury ${ }^{28}$ However, the PPV is still low. Slightly better was using a systolic BP $<40 \mathrm{~mm} \mathrm{Hg}$, which detected $76 \%$ of infants with low SVC flow, but again the PPV is low. More useful for its "rule out" value is that an infant is unlikely to have low SVC flow if the systolic BP is above $48 \mathrm{~mm} \mathrm{Hg}$ or mean BP above $40 \mathrm{~mm} \mathrm{Hg}$.

Both central and peripheral CRT had similar utility but are also imperfect predictors of low SVC flow. A central CRT $\geqslant 3$ seconds detected $55 \%$ of infants with low SVC flow but had low PPV, with only a third of the infants above this level having low flow. Increasing the cut off to four seconds increases the PPV to 55\%. There are no previous data in newborn infants relating the CRT to a measure of SBF. A study in healthy term infants in a well baby nursery in the first days after birth showed that values varied widely and depended on environmental and skin temperatures. ${ }^{8}$ In our study, an attempt was made to minimise the effect of the environment by nursing the infants in a humidified crib in 
Table 3 Diagnostic accuracy of central-peripheral temperature difference (CPTd) and capillary refill time (CRT) for prediction of low superior vena cava flow in preterm infants $<30$ weeks gestation

\begin{tabular}{|c|c|c|c|c|c|c|}
\hline & Sn & Sp & PPV & NPV & $\mathbf{L R}+$ & LR- \\
\hline \multicolumn{7}{|l|}{$\mathrm{CPTd} \geqslant 2^{\circ} \mathrm{C}$} \\
\hline 3 hours & 29 (15 to 42 ) & 78 (65 to 90 ) & 20 (8 to 32 ) & 85 (74 to 96 ) & 1.29 & 0.92 \\
\hline 10 hours & 41 (27 to 55$)$ & 66 (52 to 79$)$ & 41 (27 to 55$)$ & 66 (52 to 79$)$ & 1.19 & 0.90 \\
\hline All observations & 40 (32 to 48 ) & 69 (61 to 77$)$ & 23 (16 to 30$)$ & 83 (77 to 90 ) & 1.30 & 0.87 \\
\hline \multicolumn{7}{|l|}{$\mathrm{CRT} \geqslant 3$ seconds } \\
\hline 3 hours & 54 (45 to 63$)$ & 79 (72 to 86 ) & 23 (16 to 31$)$ & 93 (89 to 98 ) & 2.55 & 0.58 \\
\hline 10 hours & 59 (50 to 68$)$ & 75 (67 to 82 ) & 51 (42 to 60$)$ & 80 (73 to 87 ) & 2.33 & 0.55 \\
\hline All observations & 55 (50 to 60$)$ & 80 (76 to 84$)$ & 33 (29 to 38 ) & 91 (88 to 94 ) & 2.78 & 0.56 \\
\hline \multicolumn{7}{|l|}{$\mathrm{CRT} \geqslant 4$ seconds } \\
\hline 3 hours & 38 (30 to 47 ) & 93 (88 to 97) & 38 (30 to 47$)$ & 93 (88 to 97 ) & 5.24 & 0.66 \\
\hline 10 hours & 26 (18 to 33 ) & $97(93$ to 100$)$ & 77 (70 to 84$)$ & 74 (67 to 82 ) & 7.44 & 0.77 \\
\hline All observations & 29 (24 to 33$)$ & 96 (94 to 98) & 55 (50 to 60$)$ & 88 (85 to 91 ) & 6.84 & 0.75 \\
\hline
\end{tabular}

Values in parentheses are $95 \%$ confidence intervals.

$\mathrm{LR+}$, Positive likelihood ratio; $\mathrm{LR}-$, negative likelihood ratio; NPV, negative predictive value; PPV, positive predictive value; $\mathrm{Sn}$, sensitivity; $\mathrm{Sp}$, specificity.

their neutral thermal zone. Although CRT is a continuous variable, cut offs at three and four seconds were used, as this reflects the clinical accuracy of the technique. Used alone, the CRT has limited clinical utility. Combining criteria of a mean $\mathrm{BP}<30 \mathrm{~mm} \mathrm{Hg}$ or central CRT $\geqslant 3$ seconds increases the sensitivity, with $78 \%$ of infants with low flow detected. However, again the PPV is low.

In this study, CPTd did not correlate with low SVC flow in the first day after birth. To try to avoid environmental confounders, we nursed infants in their neutral thermal zones and waited 15 minutes without disturbance before measurement and avoided measurement when temperatures were changing rapidly. A previous study has suggested that CPTd is a potential early marker of cold stress after the first two to three days after birth in infants born weighing $<1000$ g. ${ }^{9}$ They noted a relatively small CPTd in the first day after birth, frequent CPTd reversals, and increased temperature fluctuations outside the normal range. No measure of blood flow was obtained. In a second study, CPTd showed a significant correlation with plasma arginine vasopressin concentration in a group of sick, very preterm infants before and after they were given volume expansion on the basis of clinically suspected hypovolaemia. ${ }^{10}$ Again no measure of circulatory filling or SBF was obtained. This study finds a complete lack of clinical utility of CPTd in the first day after birth for detecting infants with low SVC flow.

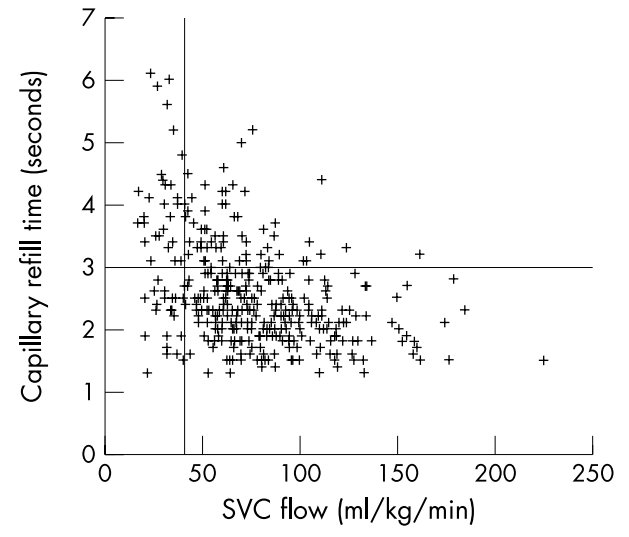

Figure 2 Scatter plot of capillary refill time against superior vena cava (SVC) flow for all observations. Reference lines represent SVC flow of $41 \mathrm{ml} / \mathrm{kg} / \mathrm{min}$ and capillary refill time of three seconds.
An important question is whether low SVC flow is a valid yardstick. This raises questions of the reliability of measuring SVC flow and the predictive value of low SVC flow for adverse clinical outcomes. Median intraobserver and interobserver variability for SVC flows were previously reported as 8.0\% and $14 \%$ respectively. ${ }^{19}$ Although it must be acknowledged

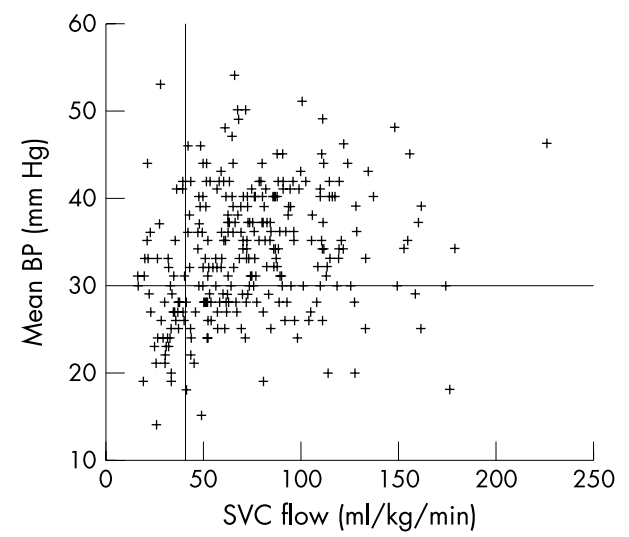

Figure 3 Scatter plot of mean blood pressure (BP) against superior vena cava (SVC) flow for all observations. Reference lines represent SVC flow of $41 \mathrm{ml} / \mathrm{kg} / \mathrm{min}$ and mean BP of $30 \mathrm{~mm} \mathrm{Hg}$.

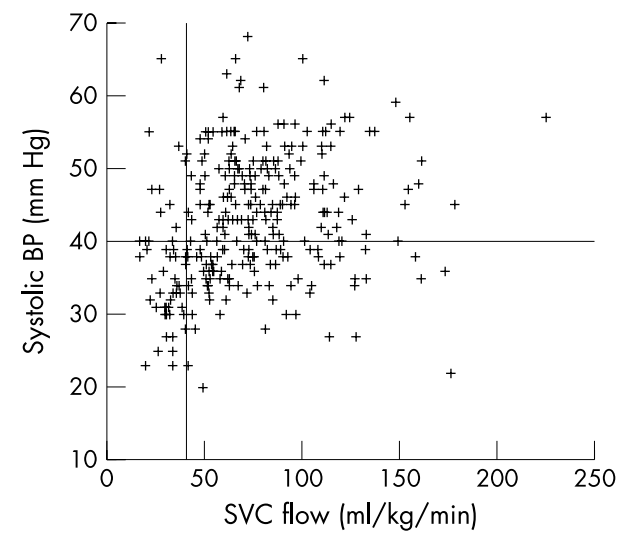

Figure 4 Scatter plot of systolic blood pressure (BP) against superior vena cava (SVC) flow for all observations. Reference lines represent SVC flow of $41 \mathrm{ml} / \mathrm{kg} / \mathrm{min}$ and systolic BP of $40 \mathrm{~mm} \mathrm{Hg}$. 
Table 4 Diagnostic accuracy of mean and systolic blood pressure for prediction of low superior vena cava flow in preterm infants $<30$ weeks gestation

\begin{tabular}{|c|c|c|c|c|c|c|}
\hline & Sn & Sp & PPV & NPV & $\mathbf{L R}+$ & $\mathbf{L}-$ \\
\hline \multicolumn{7}{|c|}{ Systolic BP $<48 \mathrm{~mm} \mathrm{Hg}$} \\
\hline 3 hours & $100(100$ to 100 & 14 (7 to 21$)$ & 15 (8 to 22$)$ & $100(100$ to 100$)$ & 1.17 & 0 \\
\hline 10 hours & 92 (87 to 97$)$ & 39 (30 to 49$)$ & 44 (35 to 54$)$ & $90(85$ to 96$)$ & 1.52 & 0.21 \\
\hline All observations & 93 (90 to 96$)$ & $35(30$ to 41$)$ & $24(19$ to 28$)$ & $96(93$ to 98$)$ & 1.43 & 0.21 \\
\hline \multicolumn{7}{|c|}{ Systolic BP $<40 \mathrm{~mm} \mathrm{Hg}$} \\
\hline 3 hours & 69 (60 to 78$)$ & 51 (41 to 61) & $18(10$ to 26$)$ & 91 (86 to 97) & 1.42 & 0.60 \\
\hline 10 hours & 81 (74 to 88 ) & 65 (56 to 74$)$ & 55 (45 to 64$)$ & 87 (80 to 93) & 2.30 & 0.29 \\
\hline All observations & 76 (71 to 81$)$ & 68 (62 to 73$)$ & 34 (28 to 39$)$ & $93(90$ to 96$)$ & 2.35 & 0.36 \\
\hline \multicolumn{7}{|c|}{ Mean $\mathrm{BP}<30 \mathrm{~mm} \mathrm{Hg}$} \\
\hline 3 hours & 62 (57 to 71$)$ & 58 (49 to 68$)$ & $19(11$ to 26$)$ & 91 (85 to 97) & 1.48 & 0.66 \\
\hline 10 hours & $62(53$ to 71$)$ & $82(74$ to 89$)$ & 64 (55 to 73$)$ & 81 (73 to 88 ) & 3.40 & 0.46 \\
\hline All observations & 59 (54 to 65$)$ & 77 (72 to 82$)$ & $36(30$ to 41$)$ & 90 (86 to 93) & 2.56 & 0.53 \\
\hline \multicolumn{7}{|c|}{$\begin{array}{l}\text { Mean } \mathrm{BP} \leqslant \text { gestation (in } \\
\text { weeks) } \mathrm{mm} \mathrm{Hg}\end{array}$} \\
\hline 3 hours & 38 (29 to 48$)$ & 76 (68 to 85$)$ & 20 (12 to 28$)$ & 89 (83 to 95) & 1.62 & 0.81 \\
\hline 10 hours & 27 (19 to 35$)$ & 92 (86 to 97$)$ & 63 (53 to 72$)$ & 71 (62 to 79$)$ & 3.2 & 0.8 \\
\hline All observations & 30 (25 to 35$)$ & 88 (84 to 91$)$ & 34 (29 to 39$)$ & $85(81$ to 89$)$ & 2.40 & 0.80 \\
\hline
\end{tabular}

Values in parentheses are $95 \%$ confidence intervals.

$\mathrm{BP}$, Blood pressure; LR+, positive likelihood ratio; LR-, negative likelihood ratio; NPV, negative predictive value; $\mathrm{PPV}$, positive predictive value; $\mathrm{Sn}$, sensitivity; $\mathrm{Sp}$, specificity.

that this reliability is that of experienced operators in neonatal echocardiography, the techniques for measuring SVC flow are relatively simple, and the vessel was chosen for its ease of measurement in the first day after birth. Low SVC flow is common in the first 24 hours after birth in extremely premature infants, ${ }^{11}{ }^{13}$ and is strongly and independently associated with subsequent $\mathrm{P} / \mathrm{IVH},{ }^{11}{ }^{13}{ }^{14}$ low urine output and hyperkalaemia, ${ }^{20}$ mortality, ${ }^{13}$ and poor neurodevelopmental outcome. ${ }^{15}$ Low SVC flow was a better predictor of $\mathrm{P} / \mathrm{IVH}^{14}$ and poor neurodevelopmental outcome ${ }^{15}$ than BP. Clearly, current evidence suggests that it is important to detect low SVC flow. All non-invasive measures have limitations to their accuracy, and SVC flow is no exception. We would argue that neonatology currently has no clinically usable haemodynamic measure that has been better validated for use as a yardstick.

However, most clinical centres do not use echocardiography in the first day after birth to determine cardiovascular status. In addition, most studies of cardiovascular interventions in preterm infants have enrolled hypotensive preterm infants and used blood pressure to determine success of treatment. ${ }^{1-6}$ Commonly used criteria for hypotension and cardiovascular intervention have included a mean BP $<30 \mathrm{~mm} \mathrm{Hg},{ }^{23} 29$ which was associated with increased mortality and cerebral injury in a cohort study. ${ }^{28}$ Other studies $^{4} 5^{30-32}$ have defined hypotension as below the range (usually the 10th centile) seen in population studies ${ }^{33}{ }^{34}$ of preterm infants. A commonly used bedside approximation of the 10th centile is a mean BP less than the gestational age in weeks or a systolic BP $<40 \mathrm{~mm} \mathrm{Hg} .^{33}$

The low correlation between blood pressure and SBF in the first days after birth has been reported previously in very premature infants. ${ }^{35}{ }^{36}$ In view of the inaccuracy of using blood pressure to identify preterm infants with low blood flow and the strong association between low upper body blood flow and adverse outcomes, ${ }^{11}{ }^{13-15}$ future studies of cardiovascular interventions in preterm infants should measure SBF. In clinical practice, no bedside test accurately identifies infants with and without low SVC flow, and reliance on these tests is likely to result in inappropriate use of cardiovascular interventions. In Australia and New Zealand, $40 \%$ of units have a neonatologist who provides an echocardiographic service that would facilitate the measurement of blood flow. ${ }^{37}$

In conclusion, CPTd did not correlate with low SVC flow in the first day after birth. BP and CRT are imperfect predictors of low SVC flow. Future studies of cardiovascular interventions in very preterm infants should measure SBF.

\section{ACKNOWLEDGEMENTS}

We thank Dräger, Australia for providing a Dräger 8000ic humidicrib and facilities to perform Dräger Thermoview continuous central and peripheral temperature monitoring.

\section{Authors' affiliations}

D A Osborn, N Evans, Royal Prince Alfred Hospital, University of Sydney, Sydney, Australia

M Kluckow, Royal North Shore Hospital, University of Sydney

Supported by the National Health and Medical Research Council of Australia and The North Shore Heart Research Foundation, Sydney, Australia.

\section{REFERENCES}

1 Subhedar NV, Shaw NJ. Dopamine versus dobutamine for hypotensive preterm infants. (Cochrane Review). Cochrane Library, Issue 1. Oxford: Update Software, 2003

2 Roze JC, Tohier C, Maingueneau C, et al. Response to dobutamine and dopamine in the hypotensive very preterm infant. Arch Dis Child 1993;69:59-63.

3 Klarr JM, Faix RG, Pryce CJ, et al. Randomized, blind trial of dopamine versus dobutamine for treatment of hypotension in preterm infants with respiratory distress syndrome. J Pediatr 1994;125:117-22.

4 Greenough A, Emery EF. Randomized trial comparing dopamine and dobutamine in preterm infants. Eur J Pediatr 1993;152:925-7.

5 Gill AB, Weindling AM. Randomised controlled trial of plasma protein fraction versus dopamine in hypotensive very low birthweight infants. Arch Dis Child 1993:69:284-7.

6 Bourchier D, Weston PJ. Randomised trial of dopamine compared with hydrocortisone for the treatment of hypotensive very low birthweight infants. Arch Dis Child Fetal Neonatal Ed 1997;76:F174-8.

7 Tibby SM, Hatherill M, Murdoch IA. Capillary refill and core-peripheral temperature gap as indicators of haemodynamic status in paediatric intensive care patients. Arch Dis Child 1999;80:163-6.

8 Raju NV, Maisels MJ, Kring E, et al. Capillary refill time in the hands and feet of normal newborn infants. Clin Pediatr 1999;38:139-44.

9 Lyon AJ, Pikaar ME, Badger $P$, et al. Temperature control in very low birthweight infants during first five days of life. Arch Dis Child Fetal Neonatal Ed 1997;76:F47-50.

10 Lambert HJ, Baylis PH, Coulthard MG. Central-peripheral temperature difference, blood pressure, and arginine vasopressin in preterm neonates undergoing volume expansion. Arch Dis Child Fetal Neonatal Ed 1998;78:F43-5.

11 Kluckow M, Evans N. Low superior vena cava flow and intraventricular haemorrhage in preterm infants. Arch Dis Child Fetal Neonatal Ed 2000;82:F188-94.

12 Meek JH, Tyszczuk L, Elwell CE, et al. Low cerebral blood flow is a risk factor for severe intraventricular haemorrhage. Arch Dis Child Fetal Neonatal Ed 1999;81:F15-18

13 Osborn DA, Evans N, Kluckow M. Hemodynamic and antecedent risk factors of early and late peri/intraventricular hemorrhage in premature infants. Pediatrics 2003;112:33-9. 
14 Evans N, Kluckow M, Simmonds $M$, et al. Which to measure, systemic or organ blood flow? Middle cerebral artery and superior vena cava flow in very preterm infants. Arch Dis Child Fetal Neonatal Ed 2002;87:F181-4.

15 Hunt RW, Evans NJ, Rieger I, et al. Low superior vena cava flow in the first 24 hours of life and 3 year neurodevelopmental outcome [abstract]. Pediatr Res 2001;49:336A.

16 Evans N, lyer $P$. Incompetence of the foramen ovale in preterm infants supported by mechanical ventilation. J Pediatr 1994;125:786-92.

17 Evans N, lyer P. Assessment of ductus arteriosus shunt in preterm infants supported by mechanical ventilation: effect of interatrial shunting. J Pediatr 1994; 125:778-85.

18 Evans N, Kluckow M. Early determinants of right and left ventricular output in ventilated preterm infants. Arch Dis Child 1996;74:F88-94.

19 Kluckow M, Evans N. Superior vena cava flow in newborn infants: a novel marker of systemic blood flow. Arch Dis Child Fetal Neonatal Ed 2000;82:F182-7.

20 Kluckow M. Evans N. Low systemic blood flow and hyperkalemia in preterm infants. J Pediatr 2001;139:227-32.

21 Dollberg S, Rimon A, Atherton HD, et al. Continuous measurement of core body temperature in preterm infants. Am J Perinatol 2000; 17:257-64.

22 Kluckow M, Evans N. Early echocardiographic prediction of symptomatic patent ductus arteriosus in preterm infants undergoing mechanical ventilation. J Pediatr 1995; 127:774-9.

23 Evans N, Kluckow M. Early ductal shunting and intraventricular haemorrhage in ventilated preterm infants. Arch Dis Child Fetal Neonatal Ed 1996;75:F183-6.

24 Kluckow M, Evans N. Ductal shunting, high pulmonary blood flow, and pulmonary hemorrhage. J Pediatr 2000;137:68-72.

25 Osborn DA, Kluckow M, Evans N. Effect of early targeted indomethacin in ductus arteriosus and upper body blood flow in the preterm infant [abstract]. Pediatr Res 2000;47:422A.
26 Osborn D, Evans N, Kluckow M. Randomized trial of dobutamine versus dopamine in preterm infants with low systemic blood flow. J Pediatr 2002; 140:183-91.

27 Newcombe RG. Interval estimation for the difference between independent proportions: comparison of eleven methods. Stat Med 1998;17:873-90.

28 Miall-Allen VM, de Vries LS, Whitelaw AG. Mean arterial blood pressure and neonatal cerebral lesions. Arch Dis Child 1987;62:1068-9.

29 Ruelas-Orozco G, Vargas-Origel A. Assessment of therapy for arterial hypotension in critically ill preterm infants. Am J Perinatol 2000;17:95-9.

30 Hentschel R, Hensel D, Brune T, et al. Impact on blood pressure and intestinal perfusion of dobutamine or dopamine in hypotensive preterm infants. Biol Neonate 1995;68:318-24.

31 So KW, Fok TF, Ng PC, et al. Randomised controlled trial of colloid or crystalloid in hypotensive preterm infants. Arch Dis Child Fetal Neonatal Ed 1997;76:F43-6.

32 Emery EF, Greenough A, Gamsu HR. Randomised controlled trial of colloid infusions in hypotensive preterm infants. Arch Dis Child 1992;67:1185-8.

33 Hegyi T, Carbone MT, Anwar M, et al. Blood pressure ranges in premature infants. I. The first hours of life. J Pediatr 1994;124:627-33.

34 Watkins AM, West CR, Cooke RW. Blood pressure and cerebral haemorrhage and ischaemia in very low birthweight infants. Early Hum Dev 1989; 19:103-10.

35 Kluckow M, Evans N. Relationship between blood pressure and cardiac output in preterm infants requiring mechanical ventilation. J Pediatr 1996; 129:506-12.

36 Pladys $\mathbf{P}$, Wodey E, Beuchee A, et al. Left ventricle output and mean arterial blood pressure in preterm infants during the 1st day of life. Eur J Pediatr 1999; 158:817-24

37 Evans N. Echocardiography on neonatal intensive care units in Australia and New Zealand. J Paediatr Child Health 2000;36:169-71. 